or making minor presentational changes to the current systems are not options."

FRANCISCO LEYVA-LEÓN

Selly Oak Hospital,

Birmingham B296JD

1 Brearley S. Specialist medical training and the European Community. $B M 7$ 1992;305;661-2. (19 September.)

2 General Medical Council. Explanatory notes on specialist training cerlificates. London: GMC, 1990.

\section{Hepatitis A vaccine}

EDITOR,-J K Anand' thought that the recommendation by $\mathrm{A}$ Tilzey and colleagues regarding vaccination for sewage workers against hepatitis $A^{2}$ may be premature as there was no published evidence that sewage workers were at high risk.

Hepatitis A has been reported in an aircraft lavatory cleaner ${ }^{3}$ and in an engineer exposed to sewage, ${ }^{+}$although it is not certain that these occupational exposures were the actual source of the infection. National surveillance data suggest that sewage workers in the United Kingdom may have an occupational risk, and a seroprevalence survey is in progress to investigate this further

Although safe procedures of work and personal protective equipment remain the primary approach to protection of employees who may be at risk, the availability of inactivated hepatitis $A$ vaccine allows an additional option.

Hepatitis A is recognised as a prescribed disease with entitlement to industrial injuries disablement benefit if acquired through exposure at work. An affected employee would also be able to pursue a claim against the employer through a civil court action. The cost of immunising an employee is about 20 pence a week, allowing for the recommended course of vaccine, staff costs, and materials, even if protection is assumed to be valid for only five years rather than the 10 years stated in the manufacturers' data sheet.

Immunisation represents good value when the possible cost of litigation is considered, but more importantly it allows an employer to offer maximal protection for the workforce deemed to be at risk. As a result, hepatitis $A$ vaccine was offered to all our employees at risk as soon as it became available. Uptake to date (first and second doses) has been $100 \%$, and there have been no reported side effects.

Occupational Health Unit,

PETER J LONGSON

Manchester Airport,

Manchester

1 Tilzey AJ, Palmer SJ, Barrow S, Perry KR, Tyrrell H, Safary A et al. Clinical trial with inactivated hepatitis $A$ vaccine and recommendations for its use. BMf 1992;304:1272-6. (16 May.)

2 Anand JK. Hepatitis A vaccine for sewage workers. $B M \mathcal{F}$ 1992;305:477. (22 August.)

3 Hepatitis vaccine. Communicable Disease Reports Weekly 1991; 1:45.

4 Viral hepatitis, England and Wales. Communicable Disease Reports Weekly 1992;2:34.

5 Hepatitis A vaccine. Communicable Disease Reports Weekly 1992;2:15.

\section{Asthma and open cast mining}

EDITOR,-J M F Temple and A M Sykes overstate the case in concluding that open cast mining has led to increased asthma in their practice population. ${ }^{1}$ Their analysis was of the weekly number of new episodes of asthma presenting in the Glynneath practice. Presumably the practice population was stable and the rise in ashma does not simply reflect a change in list size. The authors do not provide either the prevalence or the incidence of asthma and do not state whether the rise reflected more exacerbations among patients with asthma or new cases of asthma.
It seems incredible that the doctors in the practice were unaware of when mining operations started. The authors' emphasis that data were collected blind informs us that they take the hypothesis of ascertainment bias seriously, but do they dismiss it too readily? Both the community and the doctors were aware of a possible association between asthma and local industry. Indeed, the Glynneath practice presented a major report on this topic to the inquiry into the Derlwyn open cast coal site (M W Watkins et al, unpublished report) A plausible explanation of the findings is that patients' tendency to consult the practice increased after mining operations began. Moreover, the doctors were strong adherents of the hypothesis derived from their previous studies that dust from local industry was affecting their patients' health. They argued vociferously against open cast mining. Ascertainment bias may therefore have played a part in the increase in weekly episodes of asthma observed.

The most critical factor in the interpretation of cusums is the expected incidence of disease. The authors used the 25 weeks to January 1991 to derive an expected value. Were people with seasonal allergic asthma included in the derivation of this expected value? Did the quality of the data change as the audit was under way? Were quality checks performed to ensure the completeness of the data in the baseline period? These could al be important factors in triggering an alarm prematurely by underestimating the expected incidence of asthma.

In cusum charts the rate of change of the slope is all important. The curve became less steep in January 1991, and there is a suggestion that it flattened off in the spring of 1991. This suggests that the difference between the observed and expected incidence of asthma became smaller or may even have disappeared-as would be predicted if seasonal variation accounted for some of the change in gradient in the chart.

We are intrigued by the findings, which raise three important hypotheses. Firstly, the rise in episodes is an artefact due to changes in the completeness or quality of data coinciding with mining, a greater tendency to consult, or a greater tendency for the doctors to label respiratory disease as asthma. Secondly, other concomitant changes in the environment-for example, the influenza epidemic in the winter of 1990-1 - might have contributed to the rise in episodes. The third hypothesis is that coal dust does increase asthma Much more work is needed on these hypotheses before we can apply the epidemiological criteria fo causality to assess the evidence for a causal link.

$S$ J O'BRIEN

R S BHOPAL

Department of Epidemiology and Public Health,

School of Health Care Sciences, Medical School,

Newcastle upon Tyne NE2 $4 \mathrm{HH}$

Morpeth, Northumberland NE61 2PD

B A HARKIS

1 Temple JMF, Sykes AM. Asthma and open cast mining. $B M \mathcal{J}$ 1992;305:396-7. (15 August.)

EDITOR, - Though I share J M F Temple and A M Sykes's concern that industrial degradation of the environment may impair health, their interpretation of evidence from Glynneath is simplistic.'

Glynneath lies about $3.2 \mathrm{~km}$ over a mountain from Glyncorrwg. When he gave evidence to the public inquiry on open cast mining (before excavation began) Temple claimed that the prevalence of childhood asthma in Glynneath was already exceptional because his local rates seemed much higher than the $10-12 \%$ prevalence generally quoted for children aged 0-15. He ignored published evidence from Glyncorrwg which showed ${ }^{2}$ that if good general practice records were searched thoroughly (rather than relying on parents' or children's recall) $25 \%$ of children had evidence of acute or chronic reversible airways obstruction (using Levy and Bell's criteria ${ }^{3}$ ) between 5 and 16 years of age; this confirmed Strachan's even highe figure, obtained with a similar search technique. ${ }^{4} \mathrm{I}$ has been known since the early 1980s that asthma has been systematically underdiagnosed, mislabelled, and undertreated.' Though the true prevalence has probably increased, ${ }^{6}$ active search in most practices will lead to a much greater apparent increase in prevalence.

As Temple says he made himself unaware of the starting date for open cast mining north of Glynneath, despite newly generated pollution sufficien to precipitate about 120 more new episodes of asthma than would otherwise have been expected to occur, I must believe him. What I cannot believe is that his patients were similarly unaware. If a practitioner in a mining village predicts immediate mass respiratory disaster something of the sort will doubtless appear to occur.

Open cast mining is indeed a degradation of the environment, generating minimal employment at maximal environmental cost and reintroducing all the demoralising effects of industrialisation to communities that have already suffered much more than enough. These truths need no adornment with pseudoscientific mythology.

Penmaen,|Swansea SA3 2HH

JULIAN TUDOR HART

1 Temple JMF, Sykes AM. Asthma and open cast mining. BMJ 1992;305:396-7. (15 August.)

Hart JT. Wheezing in young children: problems of measurement and management. I $R$ Coll Gen Pract 1986;36:78-81.

Levy ML, Bell LC. General practice audit of asthma in childhood. BMF 1984;289:1115-6.

Strachan DP. The prevalence and natural history of wheezing in early childhood. I $R$ Coll Gen Pract 1985;35:182-4.

Speight ANP, Lee DA, Hey EN. Underdiagnosis and underspeight ANP, Lee DA, Hey EN. Underdiagnosis and un
treatment of asthma in childhood. BMJ 1983;286:1253-6.

treatment of asthma in childhood. $B M \mathcal{F}$ 1983;286:1253-6.
6 Burnley PGJ, Chinn S, Rona RJ. Has the prevalence of asthm increased in children? Evidence from the national study of increased in children? Evidence from the national
health and growth 1973-86. BMF 1990;300:1306-10.

7 Martys CK. Asthma care in Darly Dale: general practitioner audit. $B M \mathcal{1}$ 1992;304:758-60

AUTHORS' REPLY,-Some of S J O'Brien and colleagues' points have been raised previously (and answered), ${ }^{1}$ and we reply here to the additional points.

The quality of audit data is always a matter of concern, but in the checks performed throughout the study no changes in quality were detected.

O'Brien and colleagues criticise our report for its failure to provide figures for the prevalence and incidence of asthma. We emphasise that our report was deliberately and legitimately concerned with episodes of asthma, a concept of self evident importance (to both the patients and their doctor) and the only sensible clinical indicator to measure in this "before and after" study. To confuse the concepts of incidence, prevalence, and episodes is not helpful.

We chose the words of our report carefully. Yet O'Brien and colleagues' letter is littered with ill conceived statements and attributions, particularly concerning the cusum chart. The rate of change of the slope of a cusum chart is not all important - the important point is whether sustained changes in the gradient occur. Furthermore, our report clearly states how the reference value used in constructing the chart was calculated-it was not the average of the 25 weeks to January 1991 as they say. (If we had used that average, however, correct interpretation of the resultant graph would not have been impossible.) Moreover, since the periods before and after the start of mining both included a whole year, substantial seasonal effects would have been visible if present.

We too are intrigued by O'Brien and colleagues' three hypotheses. While the first (concerning bias) has been answered, the second suggests that a 'flu epidemic might have contributed to the rise in episodes. With their access to weekly returns by the Office of Population Censuses and Surveys and 
Royal College of General Practitioners, they are in a better position than us to validate or reject such a conjecture. Our information is that no such effect is evident in the figures. As for the third hypothesis, which they implicitly attribute to us, our version was that "open cast coal mining increases episodes of asthma." To distinguish between open cast coal mining and coal dust is crucial for further work.

Finally, though it would be foolish to ignore Tudor Hart's authoritative paper (and others he quotes) on the underdiagnosis of asthma, we must reiterate that our study concerned episodes and not prevalence. His comments are therefore inappropriate.

J M F TEMPLE

Glynneath,

West Glamorgan SA11 5AL

A M SYKES

University College,

Swansea

1 Correspondence. Asthma and open cast mining. $B M \mathcal{F} 1992 ; 305$ 644-5. (12 September.)

\section{Asthma deaths in New Zealand}

EDIToR,- Julian Crane and colleagues presen time trend data correlating the rise and fall of fenoterol's market share in New Zealand between 1976 and 1989 with a coinciding epidemic of death due to asthma. ${ }^{1}$ Three considerations are valuable in judging the merit of evidence from this form of data.

Firstly, the authors' argument of an effect from fenoterol would have been more convincing had the death rate followed the rise, plateau, and fall of fenoterol's market share. Of the three phases, however, only the rise during 1976-9 fits such reasoning. Moreover, that such a steep rise can be ascribed only to fenoterol is debatable. Applying the relative risk of 2.0 found in New Zealand for fenoterol during $1977-81,{ }^{2}$ we find that the "epidemic" should have increased the pre-1976 rate of $1 \cdot 5 / 100000$ to no more than $2 \cdot 0 / 100000$, lower than the peak of $4 \cdot 1 / 100000$ observed in 1979.

Secondly, other equally plausible explanations emerge from time trend analyses. For example, the initial rise could have coincided with the onset of overuse of all inhaled $B$ agonists, as a class. This would be consistent with the findings of our

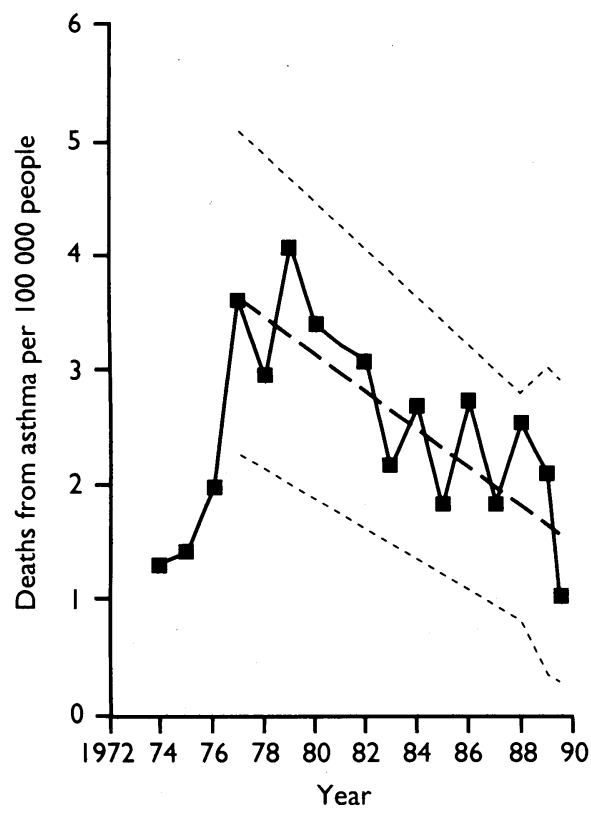

Observed rate (- - of asthma death per 100000 people aged 5-34 in New Zealand, 1974-89. Predicted rate (---) 1977-89, from linear Poisson regression, along with $95 \%$ prediction limits
Saskatchewan study of at least a tenfold increase in the risk of death from asthma in people using yearly more than one metered dose inhaler of any $B$ agonist per month, ${ }^{3}$ not only fenoterol. For the decrease in the death rate from asthma after 1977 an alternative explanation could be the more recent worldwide trend favouring the increasing use of inhaled steroids.

Lastly, Crane and colleagues submit that the drop in the death rate from asthma from $2 \cdot 2 /$ 100000 in the first half of 1989 to $1 \cdot 1 / 100000$ in the second half is significant. Instead, the appropriate scientific question should be whether the second rate for 1989 is significantly different from the rate expected taking the pre-existing 12 year decline and the yearly fluctuations into account. We fitted a linear Poisson regression model ${ }^{4}$ for the period 1977-89 and obtained 95\% prediction bands (figure). It is clear from this analysis that the rate of $1 \cdot 1 / 100000$ from the second half of 1989 falls within the range expected solely from statistical variability. Accordingly, the "drop" in the second half of 1989 is not significant, contrary to the assertion of the authors.

In summary, although the fenoterol hypothesis advanced by Crane and colleagues is possible inconsistencies in the logic, the existence of plausible alternative explanations, and inaccurate statistical analyses render it unlikely. The pitfalls inherent in time trend data analyses should be considered when assessing evidence on the risk and safety of this and other drugs.

SAMY SUISSA PIERRE ERNST

Department of Epidemiology and Biostatistics, WALTER O SPITZER

McGill University,

Department of Medicine, Montreal General Hospital,

Montreal, Quebec, Canada H3A 1A2

1 Crane J, Pearce N, Burgess C, Beasley R, Jackson R. Asthma deaths in New Zealand. BMF 1992;304:1307. (16 May.)

2 Pearce N, Grainger J, Atkinson M, Crane J, Burgess C, Culling C, et al. Case-control study of prescribed fenoterol and death from asthma in New Zealand: 1977-1981. Thorax 1990;45. $170-5$.

3 Spitzer WO, Suissa S, Ernst P, Horwitz R, Habbick B, Cockcrof $\mathrm{D}$, et al. The use of $B$-agonists and the risk of death and neardeath from asthma. $N$ Engl F Med 1992;326:501-6.

4 McCullagh P, Nelder JA. Generalized linear models. 2nd ed. London: Chapman and Hall, 1989.

EDITOR,-Julian Crane and colleagues mis represent the recent trends in mortality from asthma to defend their hypothesis that restriction on the use of fenoterol in New Zealand in 1989 led to a reduction in this mortality. ${ }^{1}$ The recent figures fall well within the $95 \%$ confidence intervals predicted by trends in mortality before 1989 in both the 5-34 and 35-55 year old populations (figure).

The research group in Wellington has always held that there was no substantive evidence that fenoterol was prescribed to patients with more severe asthma." "Channelling" occurs when patients who have either suffered adverse effects or not benefited from established treatments are prescribed a new drug. Petri et al have described channelling of inhaled $\beta$ agonists to patients differing in the severity of their asthma in the Netherlands. ${ }^{3}$ They found that $2 \cdot 0-2 \cdot 5$ times more treatment with systemic steroids and categories of other drugs for asthma was prescribed concomitantly to patients receiving fenoterol compared with those receiving salbutamol (with terbutaline intermediate). We have made a similar observation in New Zealand. ${ }^{+}$

The research group in Wellington has argued that the association between fenoterol and death due to asthma was not due to confounding by severity since the estimated relative risk for fenoterol did not decrease when the group examined the subgroups of patients with the most severe disease. This argument is inconsistent with data from the group's third study. ${ }^{5}$ Patients with
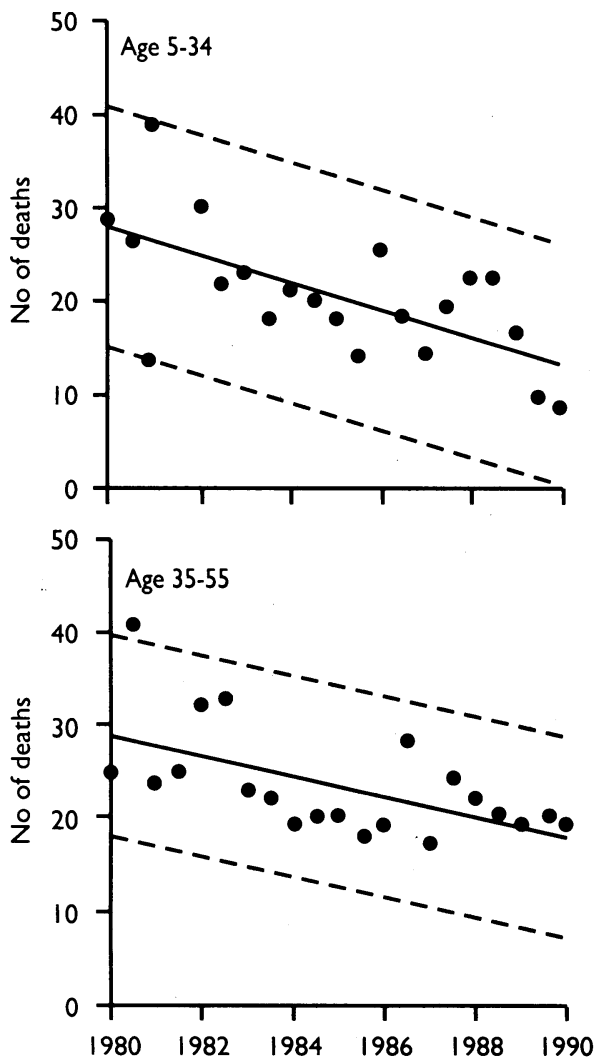

Mortality from asthma in New Zealand, 1980-90 (broken lines indicate $95 \%$ confidence intervals)

the highest baseline risk of death are those with a recent hospital admission and prescriptions for at least three classes of drugs for asthma when patients using fenoterol are excluded (relative risk=4-3). Among these high risk patients the overall relative risk for fenoterol decreases from $2 \cdot 66$ to $2 \cdot 21$. Therefore, confounding by severity of asthma cannot be excluded as a reason for the association between fenoterol and mortality from asthma. If baseline severity of asthma did increase as a result of continuous use of inhaled $\beta$ agonists or use of high doses of these drugs ${ }^{6}$ then indices of chronic severity would be intermediate in the causal pathway and would be expected to reduce the relative risk. Alternatively, the severity of asthma increased in New Zealand as a result of other factors and newer medicines for asthma, including fenoterol, were prescribed to patients with more severe asthma-that is, channelling occurred.

Crane and colleagues' letter was given wide media coverage in New Zealand before there was any opportunity of peer review. As I have shown, changes in mortality have actually been modest since use of fenoterol was restricted in New Zealand.

Department of Respiratory Medicine,

JEFF GARRETT

Green Lane Hospital,

Auckland,

New Zealand

1 Crane J, Burgess C, Pearce N, Beasley R. Asthma deaths in New Zealand. BMF 1992;304:1307. (16 May.)

2 Pearce NE, Beasley R, Burgess C, Grainger J, Crane J. Con fouding by severity does not explain the association between fenoterol and asthma death. Aust NZ J Med 1990;20(suppl 1): 515.

3 Petri H, Urquhart J, Herings R, Bakker A. Characteristics of patients prescribed three different inhalational beta- 2 agonists: an example of the channelling phenomenon. Post-Marketing Surveillance 1991;5:57-66.

4 Garrett J, Turner P. The severity of asthma in relation to beta agonist prescribing. NZ Med f 1991;104:39-40.

5 Grainger J, Woodman K, Pearce N, Crane J, Burgess C, Keane A, et al. Precribed fenoterol and death from asthma in
New Zealand, 1981-7: a further case-control study. Thorax New Zealand,

6 Sears MR, Taylor DR, Print CG, Lake DC, Li Q, Flannery EM. et al. Regular inhaled beta agonist treatment in bronchial asthma. Lancet 1990;336:1391-6. 